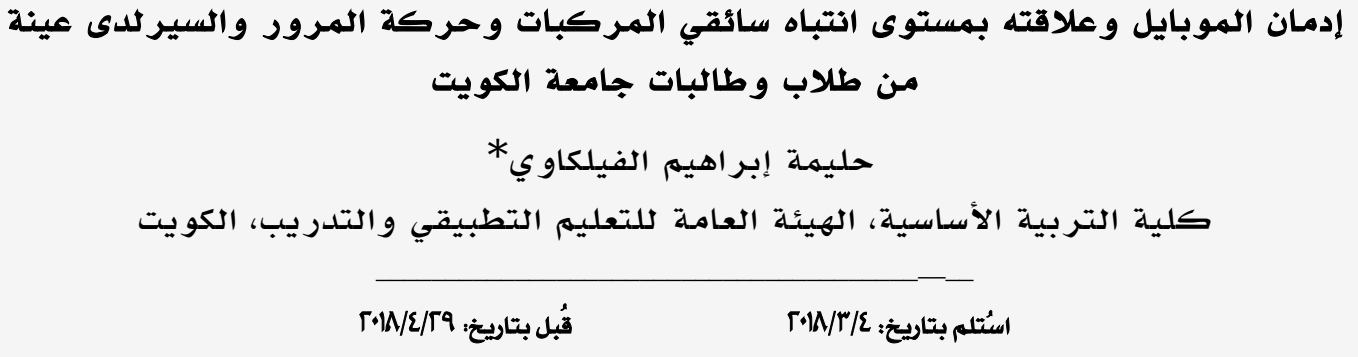

\title{
The Relation between Mobile Addiction and the Level of the Attention of Drivers to Other Vehicles and Pedestrians in a Sample of Students of Kuwait University
}

Haleama I. Al Fleakawi*

Faculty of Basic Education, General Committee for Applied Education and Training, Kuwait

Abstract: This study aimed to identify the relationship between mobile addiction - as a means of communication - with the level of the attention of drivers to other vehicles and pedestrians in a sample of students of Kuwait University. The sample of the current study consisted of 880 students of Kuwait University students, of which 440 students are addicted to mobile phones. Another 440 students who are not addicted to the mobile were characterized as "low use". The age ranges from 18-24 years. The researcher used: the mobile addiction, attention scale. The most significant results were: a statistically significant difference between the average of university students with high use and low use of mobiles in the scales of attention and driving of vehicles and traffic for the benefit of students with high use of mobile $(\mathrm{p}<0.01)$. Also, there was a negative relationship $(p<0.01)$ between the grades of students and high-level mobile use and their grades on the scales: attention and driving vehicles and traffic.

Keywords: Addiction, mobile, attention, driving vehicles, traffic and walking, university students.

*al_goori22@hotmail.com 
التدريبات البدنية، إدمان المضارية يو الأوراق المالية،

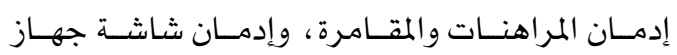

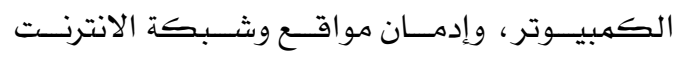

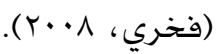
التأثيرات السلبية لإدمان الموبايل مثلما يوجـد آثار ايجابيـة لمواقع التواصل الاجتهـاعي

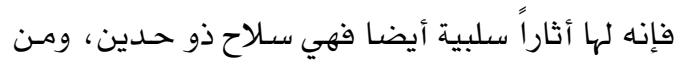

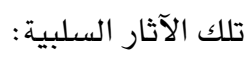

يقلل من مهارات التفاعل الشخصي. إضـاعة الوقت : حيــث أنهـا مـع خــدماتها

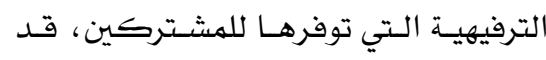
تكـون جذابـة جــا لدرجـة تتسى معهـا

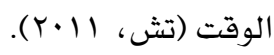
الإدمان على مواقع التواصل. ضـياع الهويـة الثقافيـة العربيـة واسـتبد الها

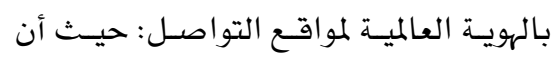

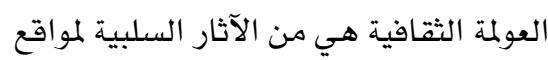
التواصل الاجتماعي بنظر الكثيرين. انعدام الخصوصية. الصداقات قد تكون مبالغا فيها أو طاغية ِِّْ بعض الأحيان. انتحال الشخصيات.

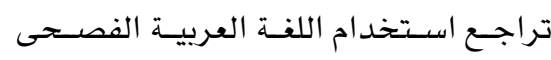

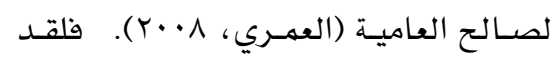

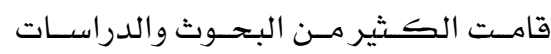

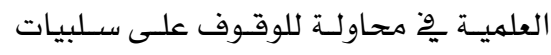

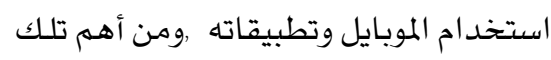

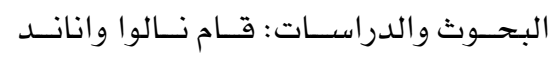

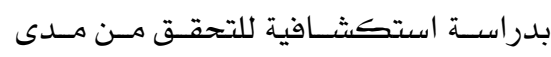

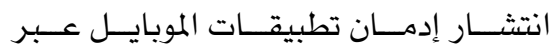

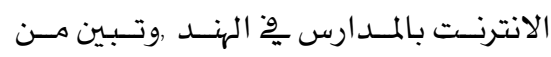

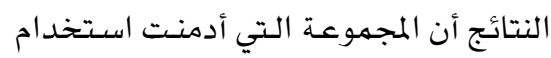

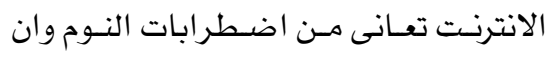

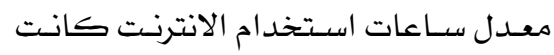

يعتبر النمـو المتســارع للحاسبـات الشخصية وصـولا إلى تكنولوجيا الإنترنت والموبايل من أهم أسباب زيادة دور

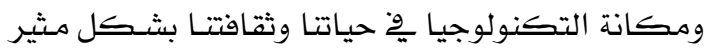
وهـــه الإثـارة جعلت الفـرد ملتصـق بالإنترنت والموبايل الأمر الذي جعله يترك الأنشطة الأخرى اليوميـة المهمهـة

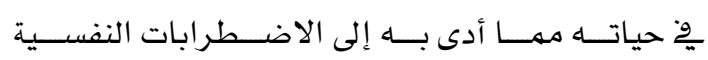

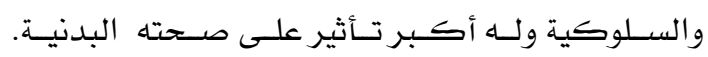

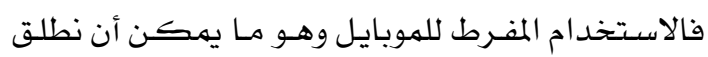

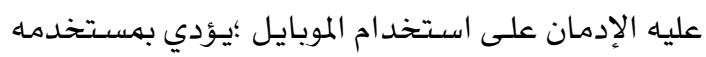

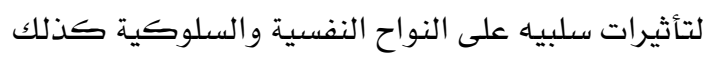

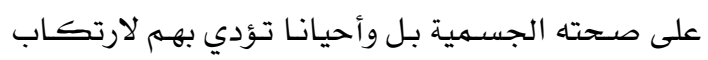

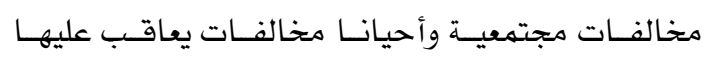
القانون نظرا لحالة التشتت التي يصابون بها مـن جـراء الإفراط بِّ استخد ام الموبايل. هذا؛ وقد تتاولت الباحثة إطارها النظري ِِّ محورين كما يلي:

\section{المحور الأول: إدمان الموبايل}

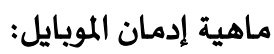

الإدمان كتعبير لفوي يشير إلى شـكل مـن أشـكال

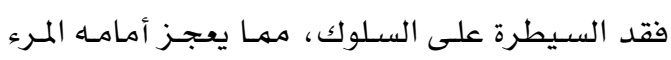

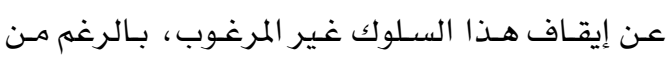

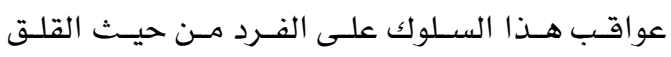

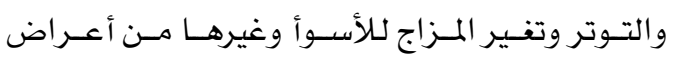

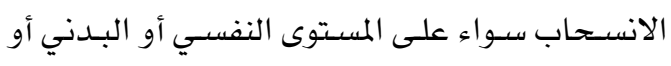

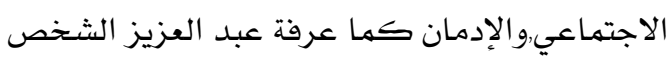

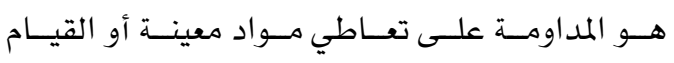

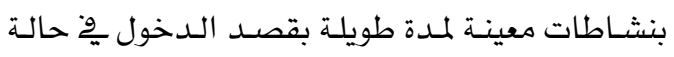

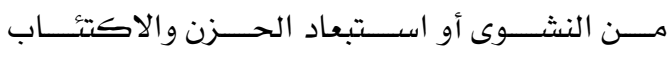

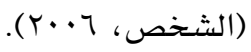

وإذا مـا نظرنـا نظـرة فاحصـة وجـادة على الأشــكال المتتوعة من الإدمان(إدمان بدون مخدرات) نجد منها فادها :

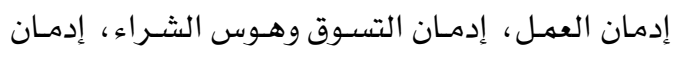

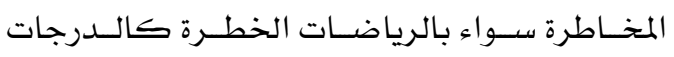

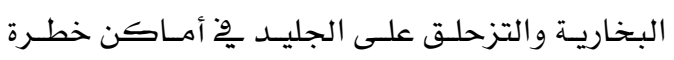

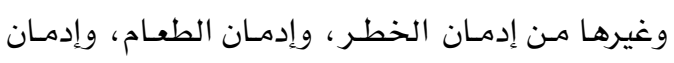




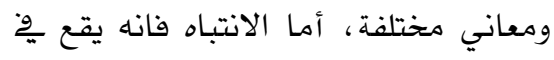
منزلة بين الإحساس و الإدراك،ولذلك الكياه يطلق على الانتباه بأنة عملية إدراكية

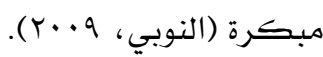

الإصفاء: وهو الخطوة الأولى قِّ عملية

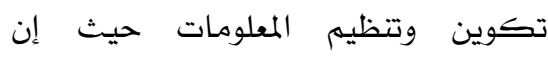
استكشاف البيئة المحيطة يتطلب من الفرد الإصغاء لبعض الأحاديث أو الأفعال

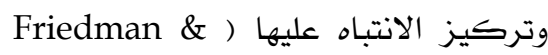
(Kock, 1985 الاختيار والانتقاء: إن الفرد لا يستطيع أن

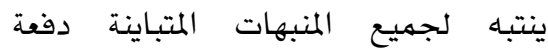

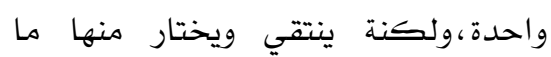
يناسب حاجاته و حالته النفسية.

عملية الإحاطة: وهي العملية السيكولوجية ذات الأساس الحسي والتي قد تكون سمعية أو بصرية، والتي تتمثل إما بِّ تحركات العينين معا عبر المكان

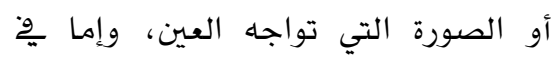

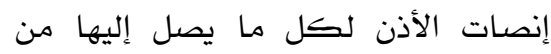

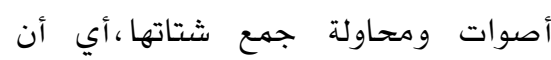

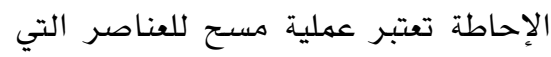

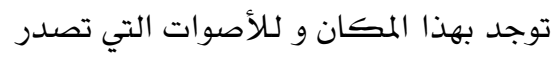

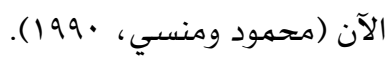
التركيز: يتمثل التركيز بِّ اتجاه الشخص بفاعلية أو ايجابية واهتمام إلى الى إثارات أو تتبيهات حسية معينة ،أو إهمال إثارات أخرى ،ويكون دائما قصديا وبؤريا، وقد يكون مركزا على منبه اخدرى

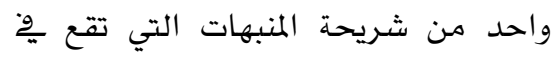

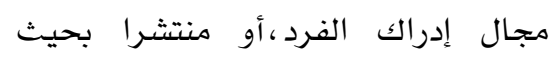

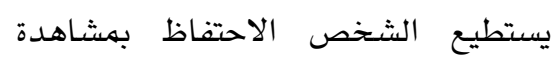

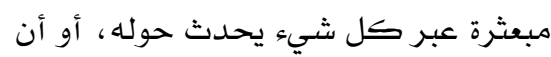

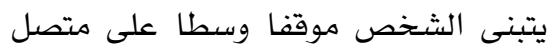
توزيع الانتباه.
كثثر من المعدل العادي · اساعات وأكثر

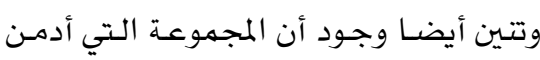

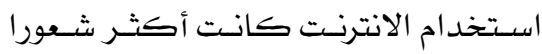
بالوحدة النفسية من الطلبة العاديين. أيضـا

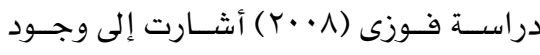

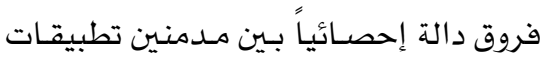
الموبايل على شبكة الإنترنت وغير المدمنين

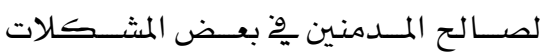
النفسـية مثـل الاكتئــاب والقلـق والتـوتر

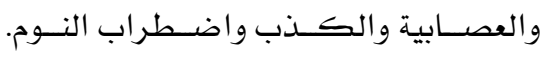

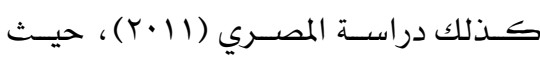

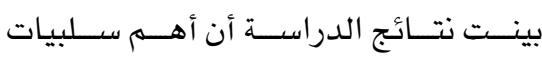

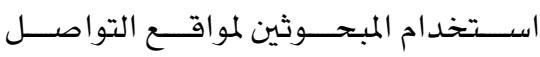

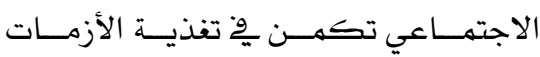
السياســية وتهيئـــة الفرصـــة لعمليــات الاسـتقطظاب مـن قبـل الآخـرين، وزيــادة

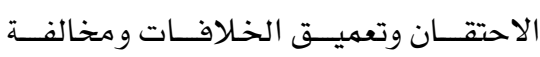

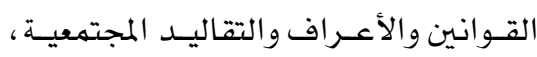

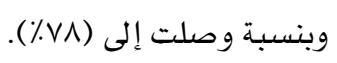
المحور الثاني: الانتباه ماهية الانتباه: عرف الشرقاوي (r..r) الانتباه بأنه:

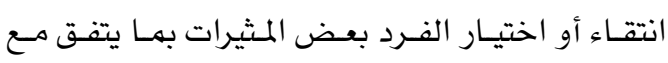

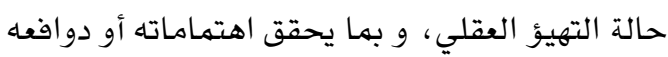

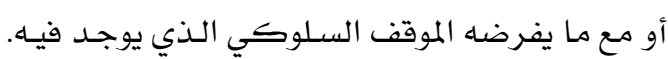

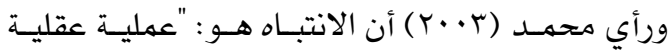

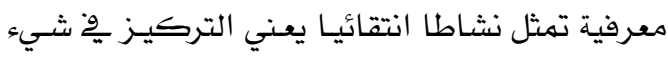

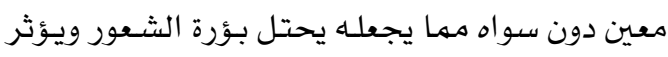
بالتـالي على أداء الفـرد". وبشــكل عـام فـان الانتبـاه

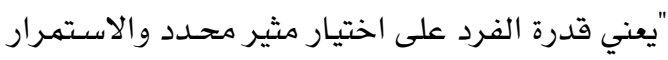

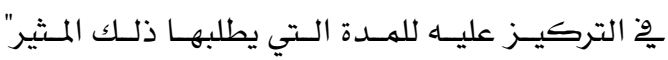

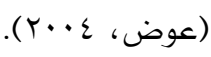

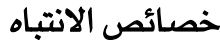

• الانتباه عملية إدراكية مبكرة: يهتم

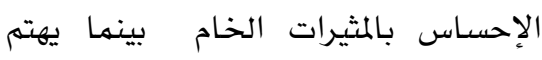

الإدراك بإعطاء هذه المثيرات تفسيرات 
خلصت الدراسة إلى أن استخدام تطبيقات الهاتف

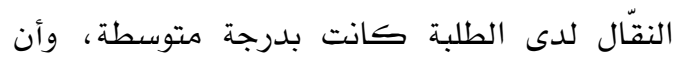

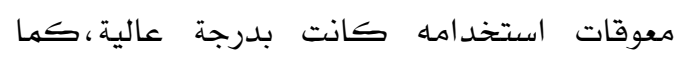
أظهرت نتائج الدراسة وجود فروق ذات دلالة

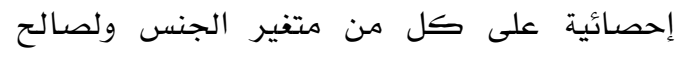

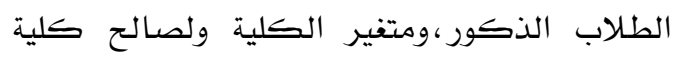
هندسة الحاسوب، وعدم وجود فروق ذات دلالة الحكونة

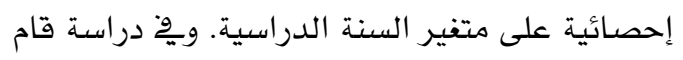

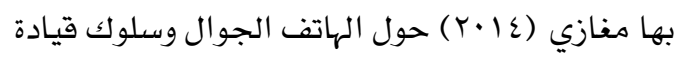
السيارات، تبين أن هناك تأثيرا عاما وأثرا مباشرا

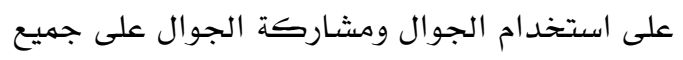

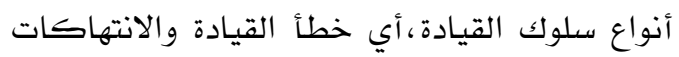

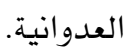

\section{بالنظر إلي مـا سبق يتضـح أن أكثر مشـكلات}

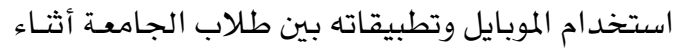
القيادة: الانتباه والالتزام بقوانين المجتمع خاصة فيما

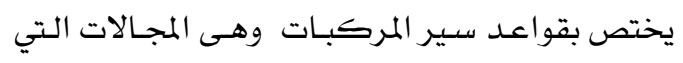

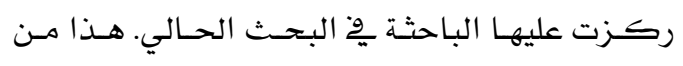

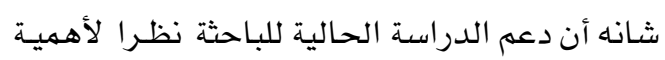

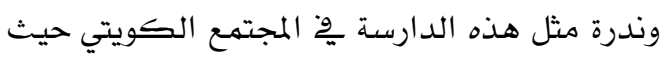
تبين لها أن موضوع الإدمـان على الموبايل لازال

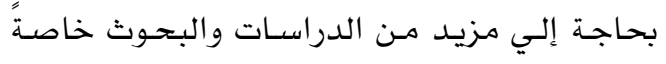

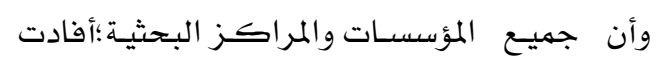

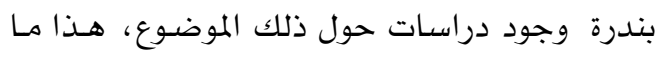
دفع الباحثة وجعل الموضوع جديرا بالدراسة والتبني

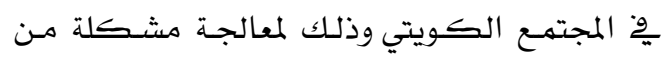
أهـم المشــكلات التربوية والنفسية التي لها تأثير

$$
\text { علي طلاب وطالبات العلم مستقبلا. }
$$

\section{مشكلة الدراسة وتساؤلاتها}

انتشـرت بشـكل ملفت شـبكة التليفونـات الجوالـة

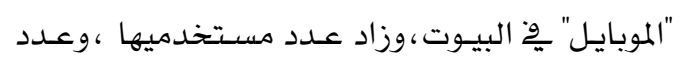

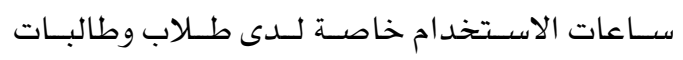

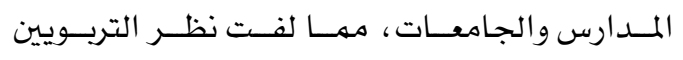

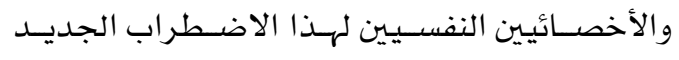

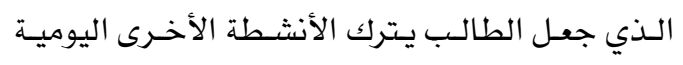

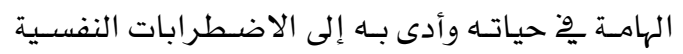

التعقب: وهو الانتباه المتصل (غير المتقطع )

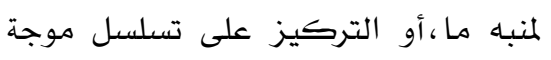
للفكر عبر فترة زمنية، والمستوى المعقد

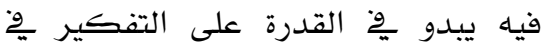
فكرتين أو أكثر، أو نمطين من المنبهات

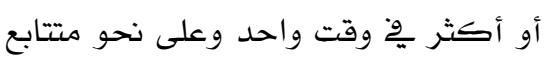

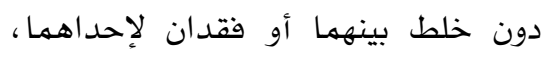
وهذا البعد ضروري ِِّْ حل المشكلات

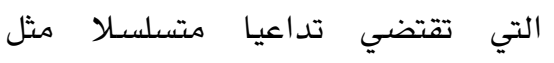

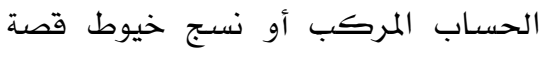
معقدة ، أو رسم اتجاهات بِّخ خريطة طرق. التموج: وهو يعني أن مصدر التتبيه

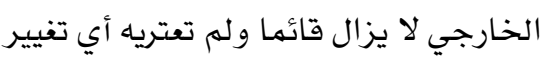
أي أن المثير مصدر التبيه رغم استمرار

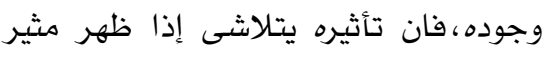

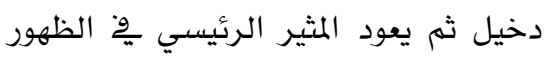
مرة أخرى عندما ينتهي وجئ يعود المئيسي

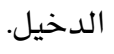
التذبذب: وهو يعني أن مستوى شدة المثير

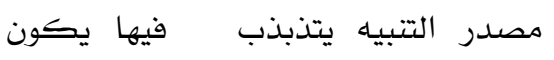
مصدر التتبيه الخارجي هو الذي يتغير

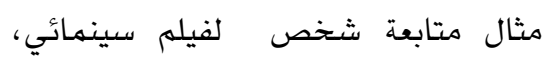
ويتابع أحداثة فان انتباهـه سوف يتذبذب لشئب

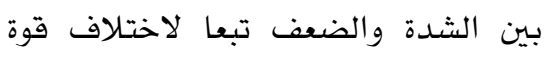

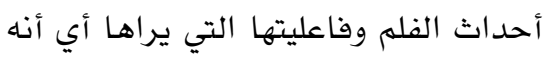

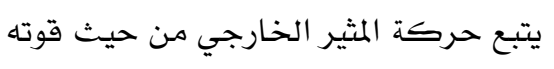
(الغباشي، • (191).

تأثير إدمان الموبايل على الانتباه: بِّ مقاله بحثيه لعبد

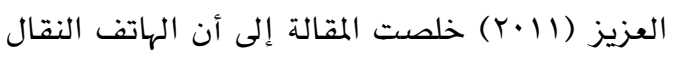

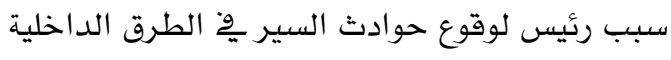

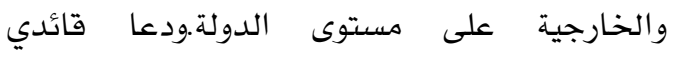
المركبات إلى عدم الانشغال أثناء القيادة بالرد على الى لئل

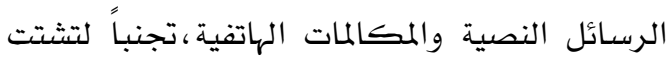
الذهن أثناء قيادة المركبة على الطريق والمفاجآت

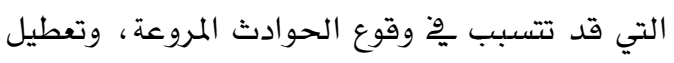

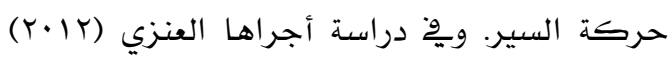


r. ترجع أهمية الدراسة أيضاً إلى أنها مـن أوائل

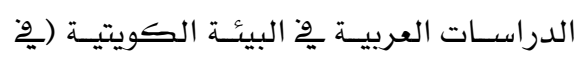
حسدود علـم الباحثـة) الــتي تتـــاول الموبايـل باعتبـاره نـوع جديـ مـن الإدمان وتـأثيره على الانتباه - وقيادة المركبات وحركة المرور

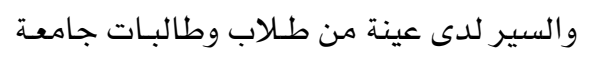

$$
\text { الكويت. }
$$

\section{الطريقة والإجراءات}

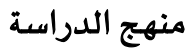

تعتمد الدراسـة الحاليـة على اسـتخدام مـهـج وصـفي

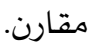

\section{عينة الدراسة}

تضـهمن مجتهـع الدراسـة طـلاب وطالبـات جامعـة

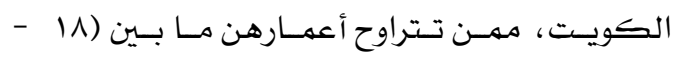

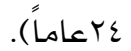

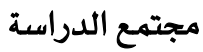

خصائص أفراد مجتمع الدراسة: النوع: من طلاب وطالبات جامعة الكويت. السن: لا يقل عن(1A)

\section{سنة، ولا يزيد عن (ع ) سنة.}

\section{عينة الدراسة}

تم اختيــار عينــة الدراســة الأسـاسـية مــن طـلاب وطالبات جامعة الكويت من بين شعب وتخصصـات علميـه ومـن شـعب تخصصـات نظريـة ، مـن إجهـالي

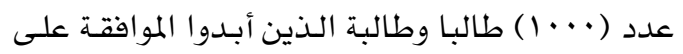

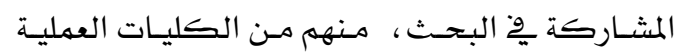

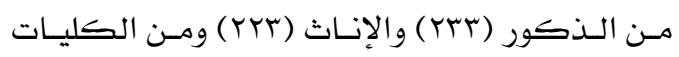

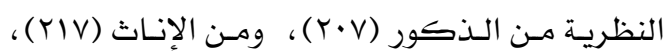

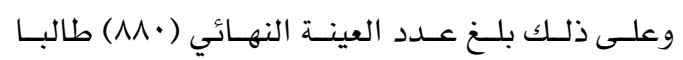

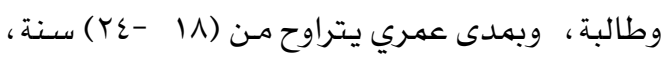
حيث تم الاختيار منهم لتحديد أفراد العينة الأسـاسية مـن الطالبـات، وفقـا لمسـتوي إدمـان الموبايـل بحسب

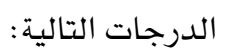

والمشــكلات السـلوكية كهـا لـه تـأثير واضـح على الصحة النفسية للفرد ، كذلك لها تأثيراتها السلبية على مـدى الالتـزام بقـوانين قيـادة المركبـات والسـير

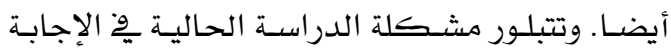

$$
\text { على التساؤلات الآتية: }
$$

ا. هل توجد فروق ترجع إلى التقاعل بـين متفير

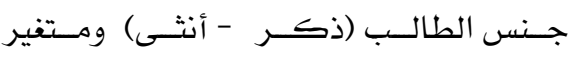

استخدام الطالب للهوبايل (منخفض-عالي)

على مقياسـي:الانتباه - قيـادة المركبـات

$$
\text { والحركة المرورية؟ }
$$

r. هل توجـد فروق دالـة إحصـائياً لـدى مرتفعي

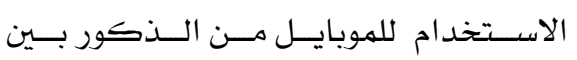

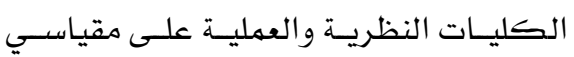
الانتباه وقيادة المركبات والحركة المرورية؟ r. هل توجـد فروق دالـة إحصـائياً لـدى مرتفعي الاستخدام للهوبايل من الإناث بين الكليات النظرية والعملية على مقياسي الانتباه وقيـادة المركبات والحركة المرورية؟ ع. هـل توجـــ علاقـة بــن مكونــات مقياسـي الانتباه وقيـادة المركبـات والحركـة المروريـة

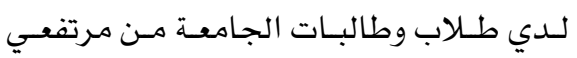

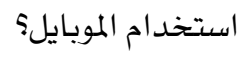

ا. ترجع أهمية الدراسـة إلى أنها ترتبط بوسيلة

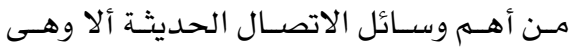
الموبايل كظاهرة منتشـرة لدى المـراهقين مـن

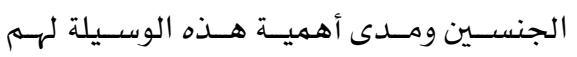
وطـريقتهم ودوافعهـم لاسـتخد امها وتأثيرهــا على الانتباه - وحركة المرور والسير. Y. ت تكهـن أهميـة الدراسـة أيضـاً إلى أن إدمـان الموبايـل أصبـح ظـاهرة مـن الظـواهر المنتشــرة

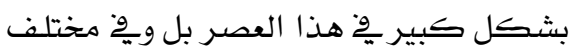
البيئات والثقافـات والمجتمعـات سـواء العربيـة

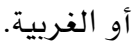


قيـادة المركبـات وحركـة المـرور والسـير: عرفت الباحثّة قيـادة المركبـات وحركـة المـرور والسـير إجرائيـا بأنهــا : تهكــن قائـد السـيـارة مـن قيـادة

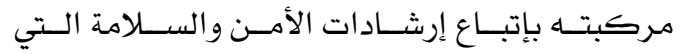

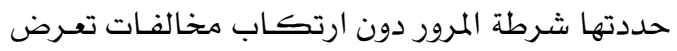

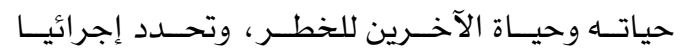
بهجهـوع الـدرجات الـتي يحصـل عليهـا المفحوصــون

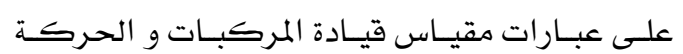
المرورية المستخدم يْ هذه الدراسة.

أدوات الدراسة مقيـاس الحركـة المروريـة: تم إعـداد هــذا المقيـاس

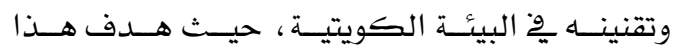

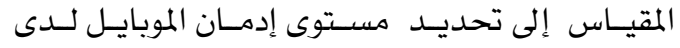
بعض الأفراد وكــلك تحديـ مـدى مسئولية إدمـان

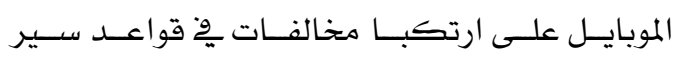
المركبات. حيث يتضهن المقياس قسمـين: القسم الأول : يتضمن البيانات الشخصية ، والتي تتضمن:

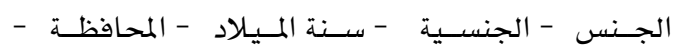

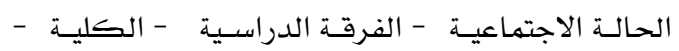

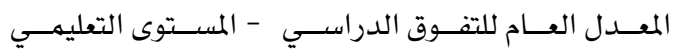

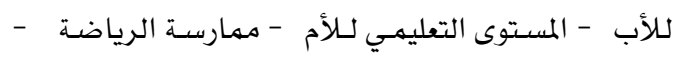

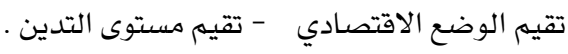
القســم النشاني :ويتضــمن مجـالات المقيـاس، والـتي تتضمن: مجال تحديد مستوى الإدمان على الموبايل:

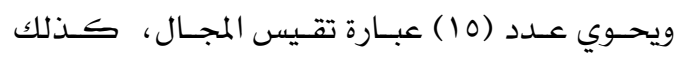
جزئيـة تقـيس حجــم الاسـتخدام اليـومي لتطبيقــات الموبايـل: مثل(انسـتفرام - فيس بـوك - سـناب تشات - تويتر).
مسـتوي إدمـان موبايـل مـنخفض :حصـول

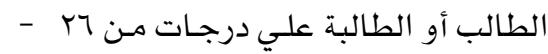
70 درجة علي مقياس إدمان الموبايل.

مسـتوي إدمـان الموبايل متوسـط :حصـول

الطالـب أو الطالبـة علـي درجـات مـن 77 - 99 درجة علي مقياس إدمان الموبايل.

مسـتوي إدمــان الموبايـل مرتفـع :حصــول الطالـب أو الطالبـة علي درجـات مـن . . - با درجة علي مقياس إدمان الموبايل .

اختارت الباحثة العينـة مـن بـين ذوي إدمـان الموبايــل المـــنخفض -والمرتفـــع -وتم

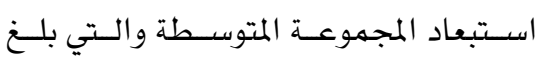

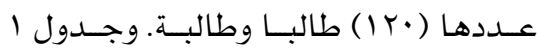
يوضــح عــدد أفـراد العينــة النهائيـة ِوِ التخصصات العهلية والنظرية.

التعريفات الإجرائية للمصطلحات

إدمان الموبايل Mobile Addiction: عرفت الباحثة إدمان الموبايل إجرائيا بأنه: ذلك الاعتياد الذي يكونه الفرد لنفسـه من خلال تفاعله النهطي والمتتكرر مع بيئة افتراضية على شاشة الموبايل، ويحدد إجرائيا بهجموع الدرجات التي يحصل عليها المفحوصون ِِّ مقياس إدمان الموبايل المستخدم بِ هذه الدراسة.

الانتباه Attention: عرفت الباحثة الانتبـاه إجرائيـا بأنها: قدرة الفرد علي تركيز حواسـاه وِّ مثير داخلي

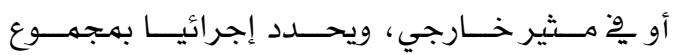
الدرجات التي يحصل عليها المفحوصون على عبارات مقياس الانتباه المستخدم يِّهذه الدراسة.

جدول 1

توزيع أفراد العينة حسب النوع والكلية والاستخدام

\begin{tabular}{|c|c|c|c|c|c|c|c|}
\hline المجموع & المجموع & \multicolumn{2}{|c|}{ الإناث } & المجموع & \multicolumn{2}{|c|}{ الذكور } & \\
\hline \multirow{2}{*}{$\leqslant r V$} & \multirow{2}{*}{ r. $r$} & نظرية & عملية & \multirow{2}{*}{ rro } & نظرية & عملية & \multirow[t]{2}{*}{ ستخدام مرتقع } \\
\hline & & $1 \ldots$ & $1 . r$ & & $9 V$ & KN & \\
\hline sor & זM & $11 \mathrm{~V}$ & $|r|$ & r10 & 11. & 1.0 & استخدام منخفض \\
\hline м. & $\varepsilon \varepsilon$. & YIV & שTr & $\varepsilon \varepsilon$. & $r \cdot v$ & זrז & المجموع الكلي للعينة \\
\hline
\end{tabular}


استبانة دوافع استخدام شبكات التواصل

الاجتهاعي إعداد عبد المنعم (د. ت.).

استبانة استخدام تطبيقات التعلم النّقال:

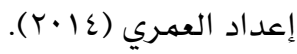

ولقد أفادت هذه المقاييس الباحثة ِّ التعرف على المؤشرات الرئيسية التي يمكن الاعتماد عليها ِِّ تصميم المقياس ؛ومن خلال ذلك تم التوصل إلى عدد من العبارات الخاصة بإدمان استخدام الموبايل وتطبيقاته.

r. تم التحديد الإجرائي لمفهوم إدمان استخدام

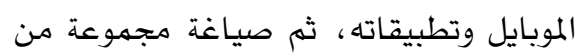
العبارات التي يمكن أن يقيسها هذا المفهوم، وراعت الباحثة أن تكون صياغة

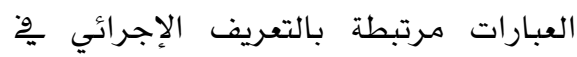
صورة مبسطة وسهلة وذات لغة مفهومة مع تحديد المعنى بدقة. ع. ثم قامت الباحثة بالخطوات التالية : تحديد الهدف العام من المقياس ِِّ التعرف على مفهوم إدمان استخدام الموبايل

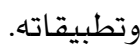

تحديد عبارات مقياس إدمان استخدام

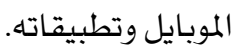

تصميم عدد من العبارات التي تتناسب والتعريف الإجرائي لعبارات مقياس إدمان استخدام الموبايل وتطبيقاته. 0. ثم قامت الباحثة باستطلاع رأي عدد (ع) من أساتذة ِِّ تخصصات علم النفس بجامعة الكويت، حيث تم تقديم العبارات لهم، مع تحديد التعريف الإجرائي لمفهوم إدمان استخدام الموبايل وتطبيقاته، وذلك للحكم الحمري على عبارات المقياس من حيث:

مناسبة العبارات بِ قياس ما صهم

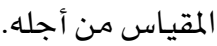

مجال تأثير إدمان الموبايل على قيادة السيارة: وهـو

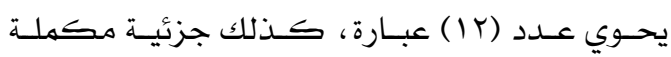
تتضـــن اختيـار الإجابـة المنـاسـبة حـول تكــرار مـا

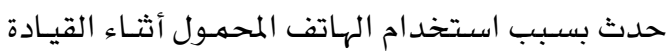
2ِ عدد (7) عبارات تتضهن احد الخيارات: كثيرا،

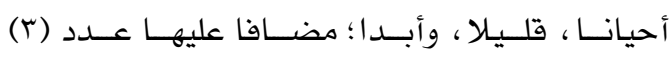
تساؤلات تتضمن الإجابة عليها احد الخيارات نعم أو ولهيات

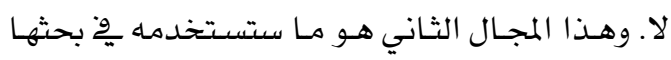

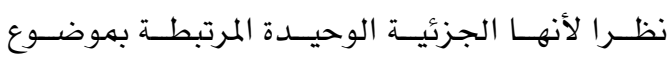

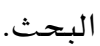

\section{مجال الأعراض الجسمية والنفسية لإدمان الموبايل:} وهو يحتوي على (·r ) عرضا يتخير المفحوص تلك الأعراض التي تتطبق عليه من خلال احد الخيارات

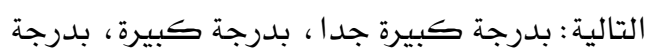
متوسطة ، بدرجة قليلة ، لا يوجد تأثير.

مقياس إدمان الموبايل: ( إعداد/الباحثة). هدف هذا

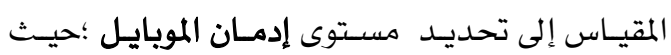
اتضـح للباحثة ندرة توافر مقياس مناسب على الرغمم من أهمية قياس مستوى استخدام الموبايل وتطبيقاته كوسـيلة مسن وسـائل الاتصــال الحديثـة، وهـن ثـم فئم

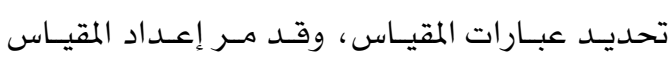

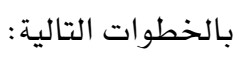

1. الاطلاع على الكتابات النظرية والتراث

السيكولوجي الخاص باستخدام الموبايل

وتطبيقاته كوسيلة من وسائل الاتصال

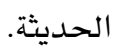

r. قامت الباحثة بإجراء مستح للبحوث

والدراسات العربية والأجنبية التي تتاولت

استخدام الموبايل وتطبيقاته كوسيلة من

وسـائل الاتصال الحديثة ومن خلال هذه

الدراسات استطاعت الوصول إلى عدد من

المقاييس التي استخدمت ِِّ قياس إدمان

استخدام الموبايل وتطبيقاته على سبيل المثال المبل المان

لا لا الحصر: 
V. التحقق من الصدق والثبات: للتحقق من صدق المقياس استخدمت الباحثة، الصدق المنطقي، حيث قامت الباحثة بعرض المقياس على (ع) من الأساتذة استة

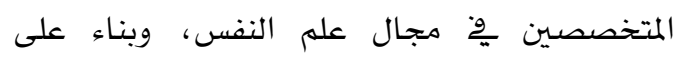
توجيهاتهم قامت الباحثة فقط بتعديل صياغة بعض آن العبارات حسب آراء المحكهـين كها تم توضيحها

سابقا.

وللتحقق من ثُبات المقياس، استخدمت الباحثة طريقة ألفا - كرونباخ، والتجزئة النصفية لسبيرمان - براون على عينة مكونة من (1999) طالبا وطالبة لحساب ثبات المقياس، حيث بلفت

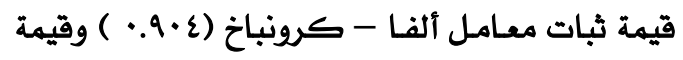
ثبات التجزئة النصفية (1TV. ·). يتضح مما سبق أنسات

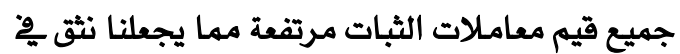

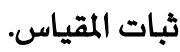
مقياس الانتباه: هدف هذا المقياس إلى تحديد مستوى الانتباه لدى طلاب وطالبات الجامعة بدولة

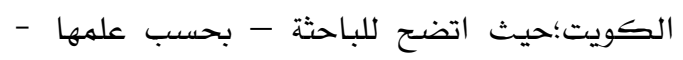
ندرة توافر مقياس مناسب على الرغم من أهمية

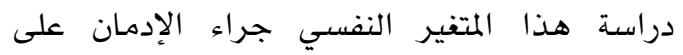
استخدام الموبايل وتطبيقاته لدى طلاب و طالبات الجامعة، وقد مر إعداد المقياس بالخطوات التالية: ا. الاطلاع على الكتابات النظرية والتراث السيكولوجي الخاصة بالمشكاتلات النفسية عامة والمشكلات النفسية جراء الإدمان على استخدام الموبايل وتطبيقاته لدى طلاب وطالبات الجامعة بدولة الكويت خاصة. r. قامت الباحثة بإجراء مستح للبحوث والدراسـات العربية والأجنبية التي تتاولت المشكلات النفسية جراء الإدمان على استخدام الموبايل وتطبيقاته ومن خلال هذه الدراسات استطاعت الوصول إلى عدد من المقاييس التي استخدمت ِِّ قياس المتغيرات النفسية على سبيل المثال لا الحصر :
مدى ارتباط العبارة بالمفهوم من حيث المضهون والصياغة وسهولة المعنى.

إضافة أي عبارات يراها المحكم لها ارتباط بالبعد ولم يرد ذئ ذهرها

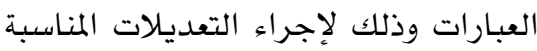
حتى يصبح المقياس صالحا للتطبيق الميداني. ولقد أسفرت هذه الخطوة عن موافقة السادة المحكهمون على غالبية عبارات المقياس بعد إجراء تعديلات بِ

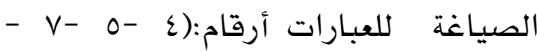
$-r Y-11-10-1 \varepsilon-1 r-9-1$ (ع) (Yr- r.- YT- YO عبارة، لذا فسيتهم الإبقاء عليها جميعا وإلغاء العبارات أرقام: (•1 - - - أو 19 لوجود تكرار بها وعددها (V) عبارات، كما تم بناء على رغبة المحكهمين تقسيم العبارة رقم (10) إلى عبارتين، وعلى ذلك لك فان عبارات المقياس أصبحت (Yr) عبارة. وضعت العبارات على تدريج خماسي طبقا لطريقة ليكرت بحيث تكون الاستجابة لكل عبارة بإحدى الاستجابات: تتطبق بشدة - تتطبق - تتطبق لحد ما - لا لاحس تتطبق - لا تتطبق بشدة. 1. وقد أعطت الباحثة لكل اختيار وزنا، بحيث تعطي الاستجابة تتطبق بشدة (0) درجات ، وتتطبق (ع) درجات، وتتطبق لحد

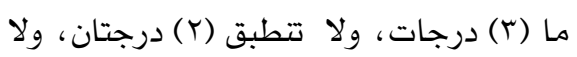
تتطبق بشدة درجة واحدة (1)، وبذلك تتراوح

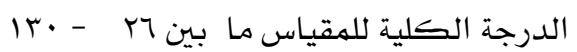
درجة وتدل الدرجة المرتفعة على المقياس على إدمان استخدام الموبايل وتطبيقاته بشكل مرتفع، بينما تدل الدرجة المنخفضة إلى استخدام الموبايل وتطبيقاته بصوره طبيعية. 
حتى يصبح المقياس صالحا للتطبيق

$$
\text { الميد اني. }
$$

ولقد أسفرت هذه الخطوة عن موافقة المحكمين

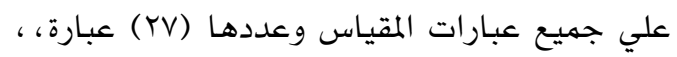
مع إجراء تعديلات عْ الصياغة فقط على بعض

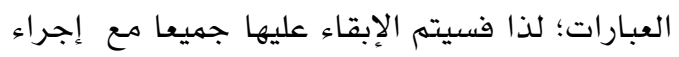
تعديل ِّْ صياغة بعض العبارات. وضعت العبارات

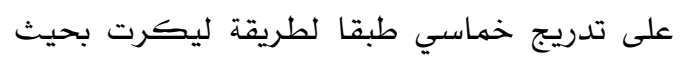
تكون الاستجابة لكل عبارة بإحدى الاستجابات: دائما-غالبا - أحيانا - نادرا - أبدا.

ثم أعدت الباحثة مفتاحا خاصا لتصحيح المقياس فقد أعطت لكل استجابة من هذه الاستجابات الخمس، وزنا بحيث تعطي الاستجابة دائها (0)

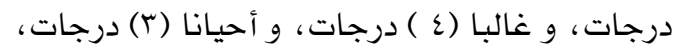
ونادرا (Y) درجتان، وأبدا درجة واحدة (1). و وبذلك

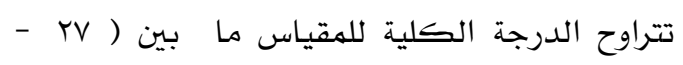

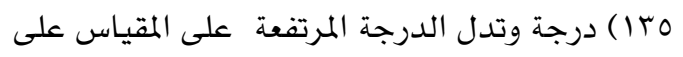
ارتقاع مستوى المثككلات الخاصة بالانتباه - قصور

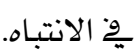
وقامت الباحثة بالتحقيق من الصدق والثبات. التحقق من صدق المقياس: للتحقق من صدق المقياس استخدمت الباحثة: الصدق المنطقي: حيث قامت

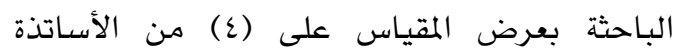

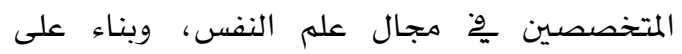
توجيهاتهم قامت الباحثة فقط بتعديل صياغة بعض آن العبارات حسب آراء الأسـاتذة المحكمهين كما تم توضيحهه سـابقا.

التحقق من ثبات المقياس: استخدمت الباحثة طريقـة

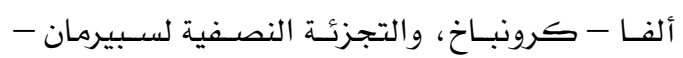
بـراون على عينـة مكونـة مـن (199 ) طالبـا وطالبـه ؛ لحسـاب ثبات المقياس، حيث بلفت قيمة ثبات معـاهل

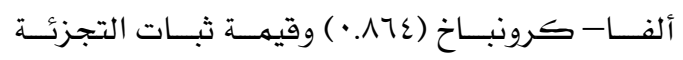

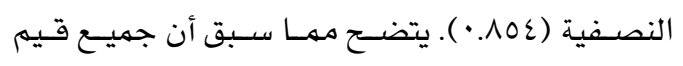

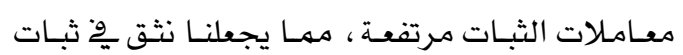
المقياس.
استبانة تقيس المشكلات السلوكية

التي يعكسها استخدام الأفراد للأجهزة الذكية من وجهة نظر ولي الأم، إعداد أبو الرب والقصيري (ع إب)

استبانة تأثير الهاتف النقال ِِّ سلوكيات

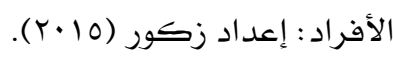

ولقد أفادت هذه المقاييس الباحثة ِِّْ التعرف على المؤشرات الرئيسية التي يهكن الاعتماد عليها ـوِ تصديم المقياس؛ ومن خلال ذلك تم التوصل إلى عدد من العبارات الرئيسية الخاصة بهتفير الانتباه. r. تم التحديد الإجرائي لمتفير الانتباه، ثم

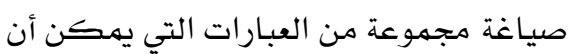
يقيسها هذا المتفير النفسي، وراعت الباحثة أن تكون صياغة العبارات مرتبطة بالتعريف الإجرائي پِّ صورة مبسطة وسهلة وذات لغة مفهومة مع تحديد المعنى بدقة. ثم قامت الباحثة بالخطوات التالية :

تحديد الهدف العام من المقياس فِّ التعرف على مستوي الانتباه لدى طلاب و طالبات الجامعة بدولة الكويت.

تحديد عبارات مقياس الانتباه بدقه لدى طلاب و طالبات جامعة الكويت.

وقامت الباحثة باستطلاع رأي عدد(ع) من الأساتذة مِّْ تخصصات علم النفس بجامعة الكويت، حيث تم تقديم العبارات لهم، هع تحديد التعريف الإجرائي؛ وذلك للحكم على عبارات المقياس من

مناسبة العبارات ف2 قياس ما صهم

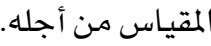

مدى ارتباط العبارة من حيث المضهون و الصياغة وسهولة المعنى.

إضافة أي عبارات يراها المحكم لها ارتباط بالبعد ولم يرد ذيرها العبارات وذلك لإجراء التعديلات المناسبة 
المركبات والحركة المروريةك. ولإجابة على هذا

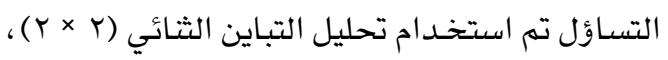
والجدولين ب و ب يوضحان ذلك.

$$
\text { نتائج الدراسة }
$$

بالنسبة للتساؤل الأول: هل توجد فروق ترجع إلي

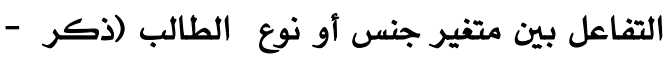
أنثى) ومتغير استخدام الطالب على الموبايل (منخفض - عالي) على مقياسي: الانتباه - قيادة البرئ

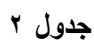

المتوسطات الحسابية والانحرافات المعيارية لأفراد عينة الدراسة على مقياسي: الانتباه - قيادة المركبات والحركة المرورية طبقا لمتغيري

\begin{tabular}{|c|c|c|c|c|c|}
\hline الانحراف المعياري & المتوسط الحسابي & العدد ال العد & مسنتى استخدام الطالب & المعالجة & المتغيـر \\
\hline ᄉ. 9 r & r9..0 & rio & منخفض استخدام الموبايل & & \multirow{4}{*}{ الانتباه } \\
\hline $1 . . r r$ & 7.94 & rro & عالي استخدام الموبايل & ذكر & \\
\hline 9.74 & $\varepsilon 9.99$ & $\varepsilon \leqslant$. & الإجمالي & & \\
\hline Q.५А & 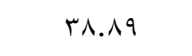 & rrA & منذفض استخدام الكوبايل & \multirow{3}{*}{ أنثى } & \\
\hline $1 \ldots 1 \varepsilon$ & ON.VT & $r \cdot r$ & عالي استخدام الموبايل & & \\
\hline 9.1 & $\{\wedge . \wedge 1$ & $\varepsilon \varepsilon$. & الإجمالي & & \\
\hline$r . .1$ & rr.s. & ro & منخفض استخدام الموبايل & \multirow{3}{*}{ ذكر } & \\
\hline$\varepsilon . \varepsilon T$ & \&1.ro & rro & عالي استخدام الموبايل & & \\
\hline r.VY & rt.rA & $\varepsilon \varepsilon$. & الإجمالي & & قيادة المركبات والحركة \\
\hline T.TE & $r r .09$ & rrA & منخفض استخدام الموبايل & \multirow{3}{*}{ أنثى } & المرورية \\
\hline r.AT & $\{\cdot, r)$ & $r \cdot r$ & عالي استخدام الموبايل & & \\
\hline $0 . . r$ & r... & $\varepsilon \varepsilon$. & الإجمالي & & \\
\hline
\end{tabular}

جدول r

تحليل التباين الثنائي لارجات الأفراد عينة الدراسة على مقياسي الانتباه - قيادة المركبات والعركة المرورية طبقا لمتغيري الجنس (ذكور

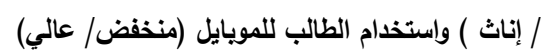

\begin{tabular}{|c|c|c|c|c|c|c|}
\hline مربع ايتا ل & مستوى الدلالة & قيمة "ت" & منوسط & درجة الحرية & مصدر الثباين & المقياس \\
\hline- & غير دالة & . TrA & ᄉ & 1 & الجنس (ذكور / إناث) & \\
\hline. .70 & $\cdots+1$ & IVA.ITr & 7.017 & 1 & 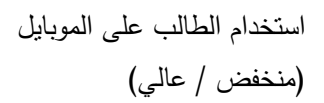 & \\
\hline$\cdots 1$ & $\cdots 1$ & A.r.T & $\begin{array}{l}\text { TYAY.NE } \\
\text { TrQ.VTE }\end{array}$ & $\begin{array}{l}1 \\
97 \\
1 . . \\
99\end{array}$ & الخطأ الكلى الكلى & الانتباه \\
\hline- & غير دالة & T.TYV & Ar.AI & 1 & الجنس (ذكور / اناث) & \\
\hline. .7 & $\cdots+1$ & IET.1YO & orso.ra & 1 & 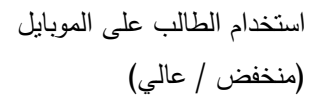 & قيادة المركبات \\
\hline$\cdots v$ & $\ldots 1$ & V.o & $\begin{array}{l}r Y \Lambda . \wedge q \\
r V .1 \Lambda \Lambda\end{array}$ & $\begin{array}{c}1 \\
97 \\
1 . . \\
99\end{array}$ & 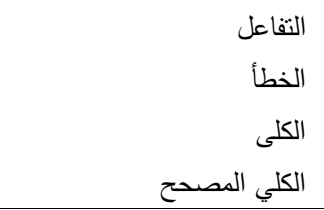 & المرورية \\
\hline
\end{tabular}


الاسـتخدام للموبايـل/ ذكـور منخفضـي الاسـتخدام

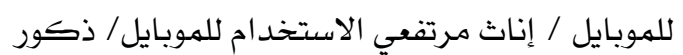
مرتقعـي الاسـتخدام للموبايـل)، ثـم قارنـت بـين هــــه

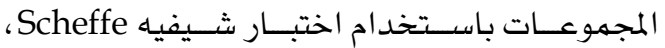
وجدول ع وه يوضحان ذلك.

يتضـح مـن جـدول ع وجـود فـروق دالـة إحصـائيا بـين متوسطات درجات كل من:

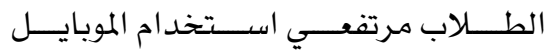
والطــلاب منتخفضـــي اسـتـخدام الموبايـلـل لصالح الطلاب مرتقعي استخدام الموبايل. الطالبــات مـرتفعــات اســتخدام الموبايـلـل . . والطالبـات منتخفضـات اسـتخدام الموبايـل لصــالح الطالبــات مـرتفعــات اســتخدام

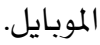

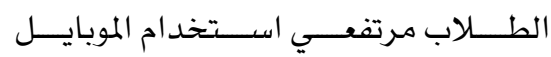

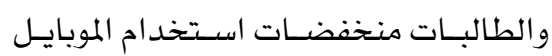
لصالح الطلاب مرتقعي استخدام الموبايل.

يتضح من جدول r ما يلي:

1. عـدم وجـود أثر دال إحصـائيا لمستفير الجـنس

(ذكـــور/ إنــاث)على مقياســــالانتباه

قيادة المركبات والحركة المرورية.

r. وجـود أثــر دال إحصـــائيا لمـتفير اســتخدام

الطالــب للهوبايـلـل (منخفض/عـــالي) علــى

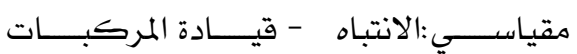
والحركة المرورية.

r. وجود أثر دال إحصـائيا للتفاعل بـين متفيري

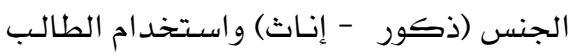

للموبايـل (منخفض/عـالي) علــ مقياســي:

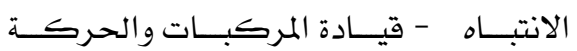

المرورية.

ولمعرفـة اتجـاه دلالــة الفـروق الـتي ترجـع للتفاعل بـين متغيري المعالجة : الجنس (ذكور / إناث) واستخدام الطالب على الموبايل (منخفض/عالي) على مقياسي:

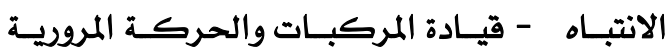
ققامـت الباحثـة بتقسـيم أفـراد العينـة طبقـا لهـذين المتفيرين إلى أربعة مجموعات فرعية (إناث منخفضي

جدول \&

دلالة الفروق بين متوسطات درجات الأفراد بالمجموعات الفرعية الأربع على مقياس الانتباه باستخدام اختبار شيفيه

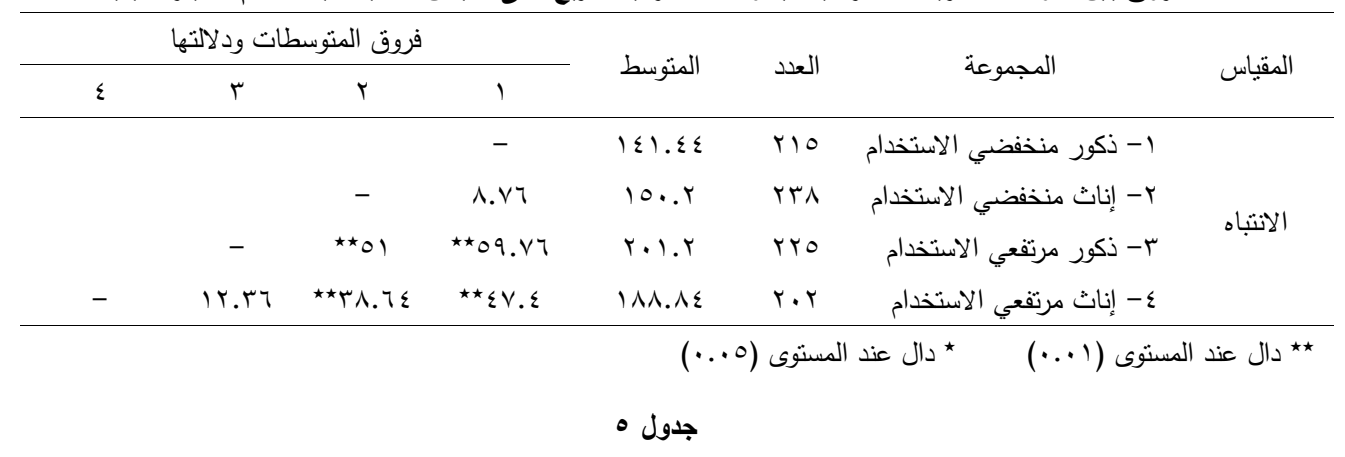

دلالة الفروق بين متوسطات درجات الأفراد بالمجموعات الفرعية الأربع على مقياس قيادة المركبات وإلحركة المرورية باستخدام اختبار شيفيه

\begin{tabular}{|c|c|c|c|c|c|c|c|}
\hline \multicolumn{4}{|c|}{ فروق المتوسطات ودلالتها } & \multirow{2}{*}{ المتوسط } & \multirow{2}{*}{ ال العدد } & \multirow{2}{*}{ المجموعة } & \multirow{2}{*}{ 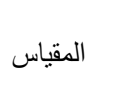 } \\
\hline$\varepsilon$ & r & r & 1 & & & & \\
\hline & & & - & 1.99 & Y10 & 1- ذكور منخفضي الاستخدام & 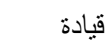 \\
\hline & & - & $1.0 r$ & $\mid r . \varepsilon \wedge$ & rth & r- إناث منخفضي الاستخدام & المركبات \\
\hline & - & זะ17. & $\star \star \mid \vee . \wedge \Lambda$ & $\curlyvee \wedge . \wedge \varepsilon$ & rro & r- ذكور مرتفعي الاستخدام & 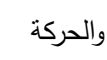 \\
\hline- & $\star 0.17$ & $\star \star 11.4$ & $\pi \star 1 t . V t$ & rт.TA & r.r & ع - إناث مرتفعي الاستخدام & المرورية \\
\hline
\end{tabular}


و الطالبــات مـرتقعــات اسـتخدـام الموبايـل والطـلاب

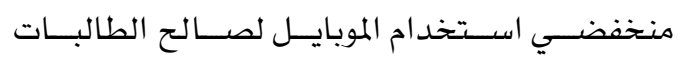

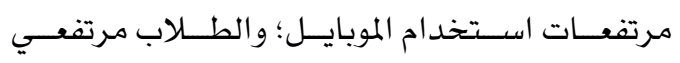

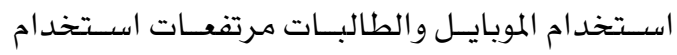

الموبايل لصالح الطلاب مرتقعي استخدام الموبايل. كهـا يتضـح مـن جـدول 0 عـدم وجـود فـروق دالـة إحصـائيا بـين متوسـطات درجـات كـل مـن: الطـلاب

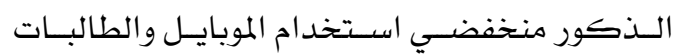
منخفضات استخدام الموبايل

وبالنسبة للتساؤل الثاني: هل توجد فروق إحصائية لدى مرتفعي الاستخدام للموبايل من الذكور بـين كليات النظرية والعملية على مقياسي الانتباه وقيادة

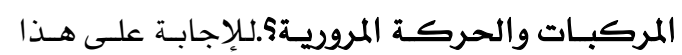

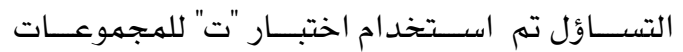
المستقلة.

تشير بيانات جدول 7 عدم وجود فرق دال إحصائيا بين متوسط درجات الكليات النظرية والعملية من طلاب الجامعة الذكور مرتفعي الاستخدام للموبايل پِّ مقياسي الانتباه وقيادة المركبات والحركة المرورية.
الطالبــات مـرتفعــات اســتخدام الموبايـلـل والطــلاب منتخفضــي اســتخدام الموبايـلـل لصــالح الطالبــات مرتفعــات اســتخدام

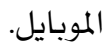
كما يتضح من جدول ع عـدم وجـود فـروق دالة إحصائيا بـين متوسـطات درجـات كل كل مـن الطـلاب الـذكور منتخفضي استخدام الموبايـل والطالبـات منخفضـــات اسـتخدام الموبايـل، والطــلاب مرتفعــي اســتخدام الموبايـل والطالبــات مـرتفعــات اسـتخدام

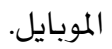
يتضـح مـن جـدول 0 وجـود فـروق دالـة إحصـائيا بـين متوســطات درجــات كـل مــن : الطــلاب مرتفعـي اسـتخدام الموبايـلـل والطــلاب منتخفضــي اسـتـخدام

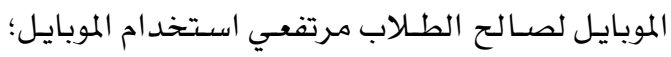
والطــلاب مـرتفعـي اســتخدام الموبايـلـ والطالبــات منخفضات استخدام الموبايل لصالح الطلاب مرتفعي

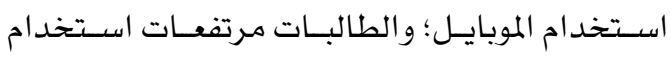
الموبايـلـ والطالبــات منخفضـــات اســتخدام الموبايـل

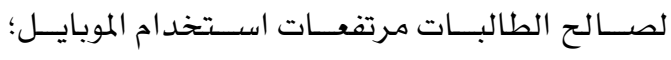

جدول 1

يوضح الفرق لاى مرتفعي الاستخدام للمويايل من الذكور بين الكليات النظرية وإلعملية على مقياسي الاتتباه وقيادة المركبات

\begin{tabular}{|c|c|c|c|c|c|c|}
\hline \multicolumn{7}{|c|}{ والحركة المرورية } \\
\hline مستوى الدلالة & قيمة "ت" & $\varepsilon$ & 5 & 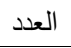 & مجموعة المقارنة & المقياس \\
\hline \multirow{2}{*}{ غير دالة } & \multirow{2}{*}{1.509} & $1 \leq . \varepsilon 1$ & $\varepsilon \wedge . \Gamma$. & $9 \vee$ & كليات نظرية & \multirow{2}{*}{ الانتباه } \\
\hline & & $17 . \wedge 9$ & 0.7. & ITA & كليات عملية & \\
\hline \multirow{2}{*}{ غير دالة } & \multirow{2}{*}{ I.TYA } & 1.7. & $r . .99$ & $9 \vee$ & كليات نظرية & قيادة المركبات والحركة \\
\hline & & 9.19 & rT.TI & IrA & كليات عملية & المرورية \\
\hline
\end{tabular}

جدول

يوضح الفرق لاى مرتفعي الاستخدام للمويايل من الإناث بين الكليات النظرية والعملية على مقياسي الانتباه وقيادة

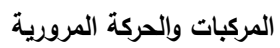

\begin{tabular}{|c|c|c|c|c|c|c|}
\hline مستوى الدلالة & قيمة "ت" & $\varepsilon$ & 5 & العدد & مجموعة المقارنة & المقياس \\
\hline \multirow{2}{*}{ غير دالة } & \multirow{2}{*}{$1.01 \leq$} & IT.Vo & ะ१.VY & $1 \ldots$ & كليات نظرية & \multirow{2}{*}{ الانتباه } \\
\hline & & $1 \leq . \wedge 7$ & $\leq 7.94$ & $1 \cdot r$ & كليات عملية & \\
\hline \multirow{2}{*}{ غير دالة } & \multirow{2}{*}{ I.YAT } & ৭.^r & r..9. & $1 \ldots$ & كليات نظرية & قيادة المركبات والحركة \\
\hline & & $11.1 \varepsilon$ & $r . .10$ & $1 \cdot r$ & كليات عملية & المرورية \\
\hline
\end{tabular}


استخدام الموبايل والطالبات منخفضات استخدام الموبايل لصالح الطالبات مرتفعات استخدام الموبايل. الطلاب مرتفعي استخدام الموبايل والطالبات منخفضات استخدام الموبايل لصالح الطلاب مرتفعي مري استخدام الموبايل. الطالبات مرتفعات استخدام الموبايل والطلاب منخفضي استخدام الموبايل لصالح

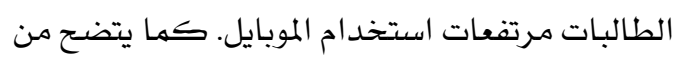
جدول V عدم وجود فروق دالة إحصائيا بين متوسطات درجات كل من:الطلاب الذكور منخفضي استخدام الموبايل والطالبات منخفضات استخدام الموبايل. الطلاب مرتقعي استخدام الموبايل والطالبات مرتفعات استخدام الموبايل على مقياس الم فوبل الانتباه، وِّ حين وجدت فروق على مقياس قيادة المركبات لصالح الذكور.

ويمكن تفسير نتائج الإجابة على التساؤل الأول الخاصة بوجود فروق بين الطلاب أو الطالبات مرتفعي استخدام الموبايل ومنخفضي استخدام الموبايل لصالح مرتفعي استخدام الموبايل، وعدم وجود فروق بين الطلاب أو الطالبات منخفضي استخدام الموبايل ِخ ضوء أن طلاب وطالبات الجامعة من ذوي الاستخدام المرتفع للموبايل "مدمني الموبايل" لديهم مستوى منتخض الانتباه والذي يتمثل دوي الدئ

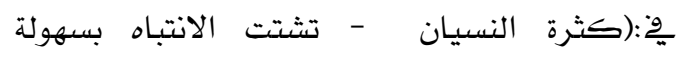

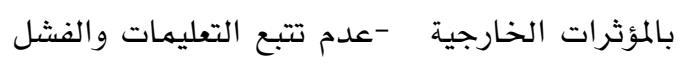
مِ إنهاء ما يطلب منهم -تجنب الارتباط بالمهام التي تتطلب مجهودا ذهنيا مستمرا -صعوبة وِ

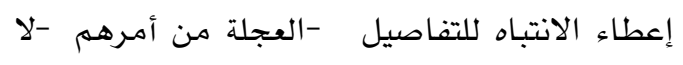
يظهر علي وجههم تعبيرات تشير إلي شـدة انتباههم -تقلت منهم الإجابات بدون تفكير حتى لقيرير

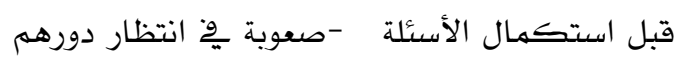

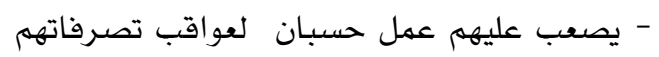
الخطأ - يصعب عليهم نقل الانتباه من مثير إلي

$$
\text { مثير آخر بسرعة). }
$$

كذلك لديهم قصور بِ القدرة على قيادة المركبات والحركة المرورية نظرا لانشغالهه بأمور أخرى غير القيادة والتي تتهثل ِِّ: (استخدام خرائط قوقل
بالنسبة للتساؤل الثالث: هل توجد فروق إحصائية

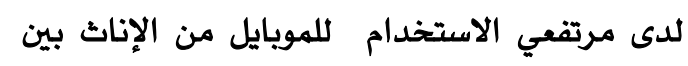
كليات النظرية والعملية على مقياسي الانتباه وقيادة المركبات والحركة المرورية؟ للإجابة على هذا

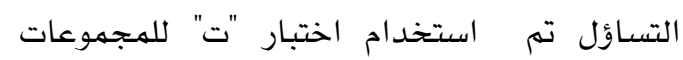
المستقلة.

تشير بيانات جدول V عدم وجود فرق دال إحصائيا بين متوسط درجات الكليات النظرية والعملية من طلاب الجامعة الإناث مرتفعي الاستخدام للموبايل وِّ مقياسي الانتباه وقيادة المركبات والحركة

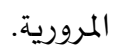

وبالنسبة للتساؤل الرابع: هل توجد علاقة بين

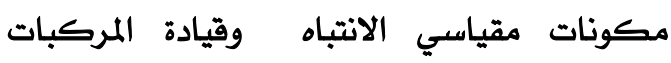
والحركة المرورية لدي طلاب وطالبات الجامعة

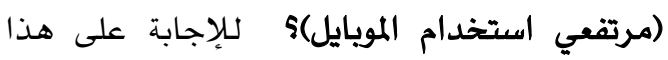
التساؤل قامت الباحثة بحساب معاملات ارتباط بيرسون بين مقياس الانتباه، ومقياس قيادة المركبات والحركة المرورية.حيث وجدت أن قيمة ليرنة معامل الارتباط بين الانتباه والحركة المرورية لطلاب ولطالبات الجامعة (العينة ككل) -09. وهي ذات دلالة إحصائية عند مستوى1 •.•، بهعنى

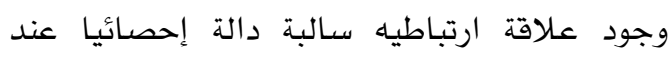
مستوى دلالة (1 •.• بين درجات الطلاب و الطالبات مرتفعي استخدام الموبايل ودرجاتهم على مقياسي: الانتباه وقيادة المركبات والحركة المرورية.

\section{مناقشية النتائج}

بالنسبة للتساؤل الأول: هل توجد فروق ترجع إلي

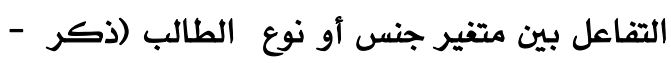
أنثى) ومتغير استخدام الطالب على الموبايل (منخفض - عالي) على مقياسي: الانتباه - قيادة المركبات والحركة المرورية؟ حيث أظهرت النتائج وجود فروق دالة إحصائيا بين متوسطات درجات كل من: الطلاب مرتفعي استخدام الموبايل والطلاب منخفضي استخدام الموبايل لصالح الطلاب

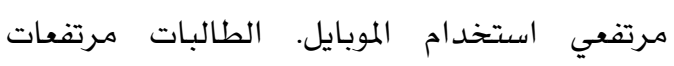


والحركة المرورية. ما توصلت إليه نتائج الدراسة

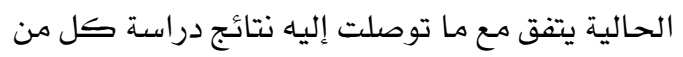

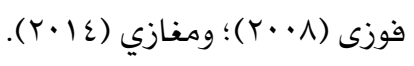

ويمكن تفسير عدم وجود فرق دال إحصائيا بين متوسط درجات طلاب وطالبات الجامعة ذوي

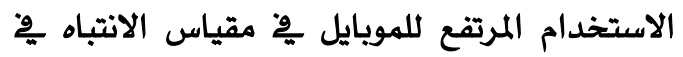

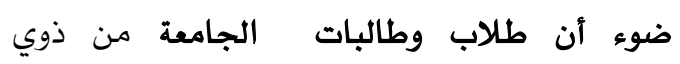

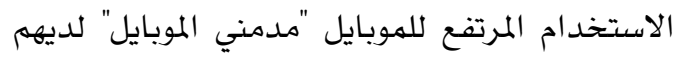

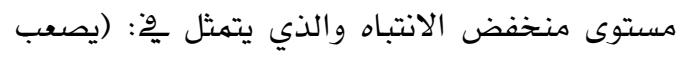
عليهم استمرار انتباهه علي المؤثرات البصرية

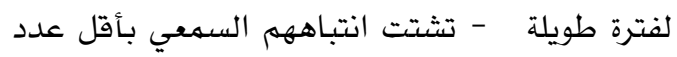

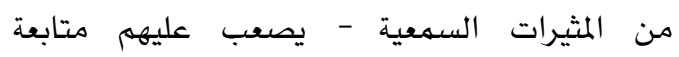
التعليمات التي تصدر عن الآخرين - لا يستجيبون بسرعة لمن ينادينهم وكأنهم أصماء - يقومون بسلوكيات تعرض حياتهم إلي الخطر - يتسرعون

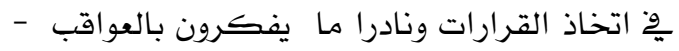

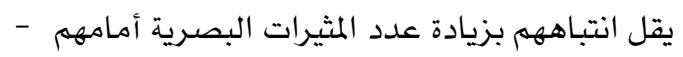
يحتاجون إلي تكرار التوجيهات اللفظية اكتر من

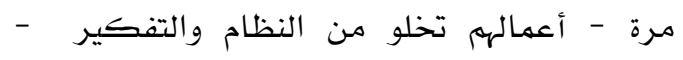

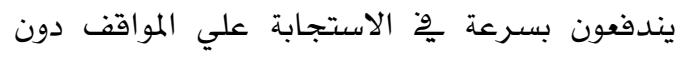

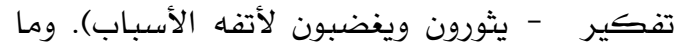
توصلت إليه الدراسة الحالية يتفق مع ما توصلت إليه

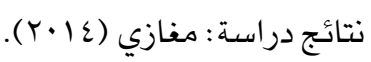

أما بالنسبة لوجود فرق بينهما على مقياس وقيادة المركبات والحركة المرورية عند مستوى دلالة ه •. لصالح الطلاب فبرغم ما أكدت عليه نتائج الفرض الأول والثاني من وجود تدن لمستوى القدرة لكليهما وِّ قياد المركبات والحركة المرورية إلا أن الطلاب عند مقارنتهم بالطالبات وِّ هذا المقياس هم أعلى بو تدني مستوى القيادة للمركبات وأكثر تسببا ِوِ مشكلات السير والتي تتمثل ِِّ: (استخدام خرائط قوقل Google map - الرد على المكالمات بدون سماعات أثناء القيادة للمركبة -كذلك استخدم تطبيقات للموبايل متتوعة :كالواتس آب، استخدم سناب شات، استخدم انستغرام، استخدم تويت،

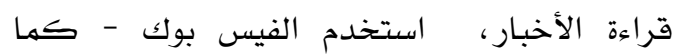

- Google map

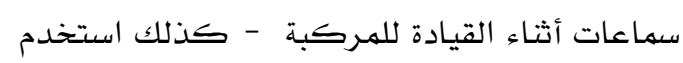
تطبيقات للموبايل متتوعة: كالواتس آب، استخدم

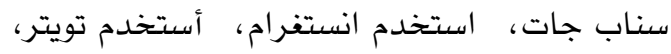
قراءة الأخبار، استخدم الفيس بوك - كما المات

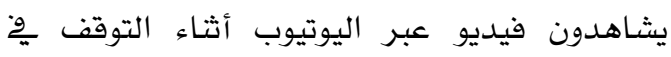

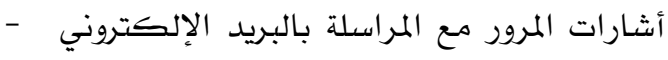
إجراء مكالمات بدون سماعات)، والتي من شأنها أسهمت بِّ مستوي مرتفع من مشكلات الانتباه وقيادة المركبات الحركة المرورية .

مِ حين أن طلاب وطالبات الجامعة من ذوي

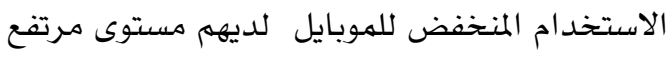

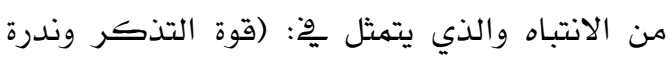
النسيان - تركيز الانتباه وعدم التشتت سهولة

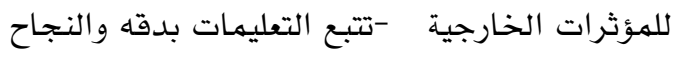

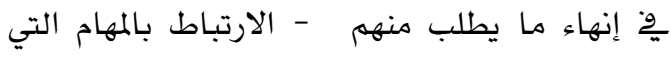

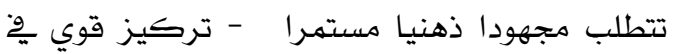

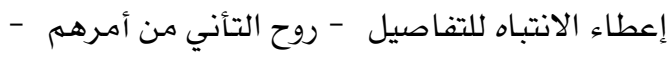
يظهر علي وجهم تعبيرات تشير إلي شدة الاتباه

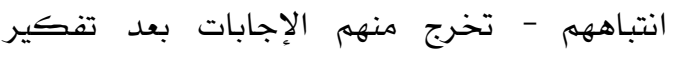

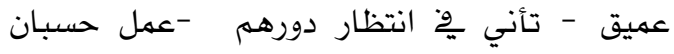
لعواقب تصرفاتهم الخطأ - نقل الانتباه من مثير إلي مثير آخر بسرعة - استمرار انتباههم علي المؤثرات البصرية لفترة طويلة كذلك لديهم قدرة جيدة على قيادة المركبات

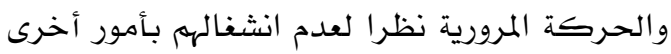

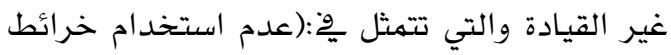
قوقل Google map -عدم الرد على المكالمات

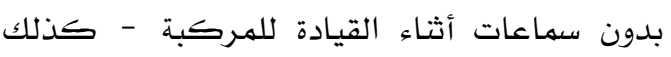

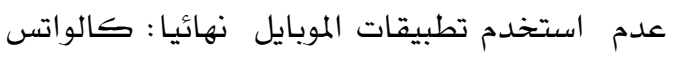
آب، سناب جات، انستغرام، تويت، قراءة الأخبا، الفيس بوك - كما أنهم يمتتعون عن مشاهدة

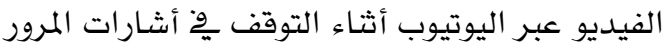

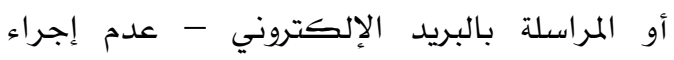

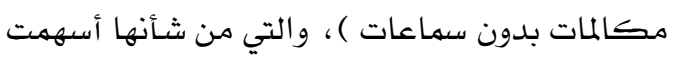
20ْ مستوي منخفض من مشكلات الانتباه 
يطلب منهم -تجنب الارتباط بالمهام التي تتطلب

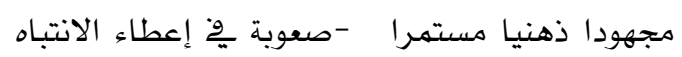

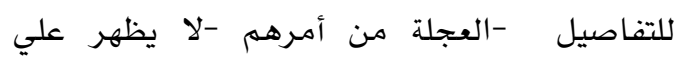
وجههم تعبيرات تشير إلي شدة انتباههم -تفلت منهم الإجابات بدون تفكير حتى قبل استكمال الأسئلة -صعوبة مِّ انتظار دورهم - يصعب عليهم عمل بل حسبان لعواقب تصرفاتهم الخطأ - يصعب عليهم نقل الانتباه من مثير إلي مثير آخر بسرعة - يصعب عليهم استمرار انتباههم علي المؤثرات البصرية البهرية لفترة طويلة - تشتت انتباههم السمعي بأقل عدد المهرد من المثيرات السهعية - يصعب عليهم متابعة

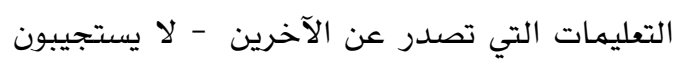
بسرعة لمن ينادينهم وكأنهم أصماء - يقومون بسلوكيات تعرض حياتهم إلي الخطر - يتسرعون

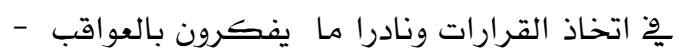
يقل انتباههم بزيادة عدد المثيرات البصرية أمامهم -

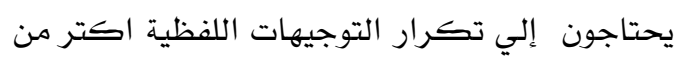
مرة - أعمالهم تخلو من النظام والتفكير يندفعون بسرعة ِو الاستجابة علي المواقف دون تقكير - يثورون ويغضبون لأتفه الأسباب).

كذلك لديهم قصور ِِ القدرة على قيادة المركبات والحركة المرورية نظرا لانشغالهم بأمور أخرى والتي تتمثل بِّ: (استخدام خرائط قوقل

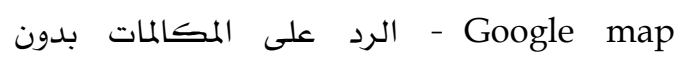
سماعات أثناء القيادة للمركبة -كذلك استخدم تطبيقات للموبايل متتوعة: كالواتس آب، استخدم سناب جات، استخدم انستغرام، استخدم تويتر،

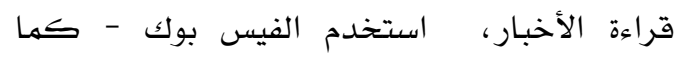

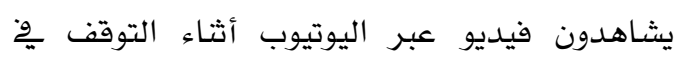

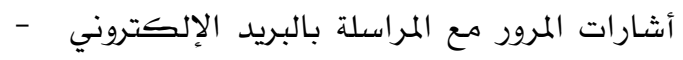
إجراء مكالمات بدون سماعات - بل ويقومون بالتصوير من جهاز المحمول - كثيرا ما تقوم السيارات بتتبيههم بحكم كونهم ساهيين أثناء

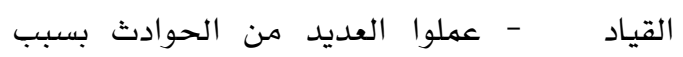
استخدامهم للهاتف المحمول)، والتي من شـأنها

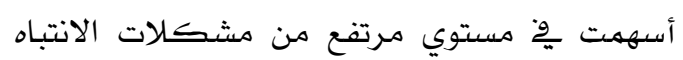

يشاهدون فيديو عبر اليوتيوب أثناء التوقف وِ أشارات المرور مـع المراسلة بالبريد الإلكتروني إجراء مكالمات بدون سماعات - بل ويقومون

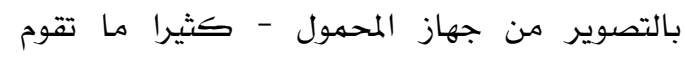
السيارات بتتبيههم بحكم كونهم ساهيين أثناء

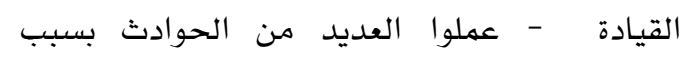

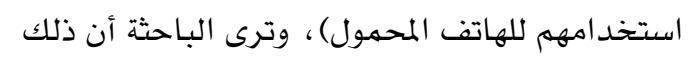
ريما يعود للحرية والجرأة التي يتمتع بها الذكر عن الأنثى خاصة يْ مجتهعاتتا العربية وروح المفامرة التي

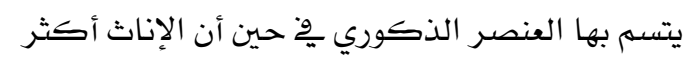
خوفا وحذرا وحيطة أثناء القيادة حتى ولو كن مدمنات للهوبايل، وتتفق هذه النتيجة مع ما توصلت إليه نتائج دراسـة العنزي (Y ( • (Y).

بالنسبة للتساؤل الثاني والثالث :هل توجد فروق

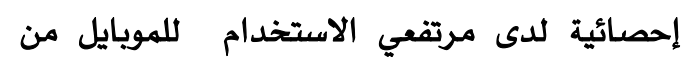
الذكور بين كليات النظرية والعملية على مقياسي

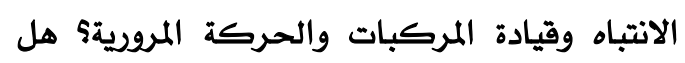
توجد فروق إحصائية لدى مرتفعي الاستخدام للموبايل من الإناث بين كليات النظرية والعملية على لودي مقياسي الانتباه وقيادة المركبات والحركة المرورية؟ فقد أشارت النتائج إلى: عدم وجود فرق دال إحصائيا بين متوسط درجات الكليات النظرية والعملية من طلاب الجامعة الذكور مرتفعي

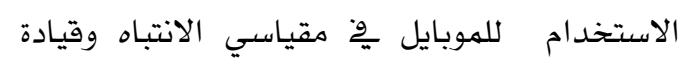
المركبات والحركة المرورية.كذلك عدم وجود فرق دال إحصائيا بين متوسط درجات الكليات النظرية

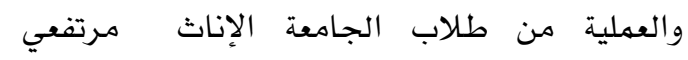
الاستخدام للموبايل وِّ مقياسي الانتباه وقيادة المركبات والحركة المرورية.

ويمكن تفسير نتائج الإجابة على التساؤل الثاني

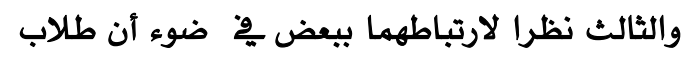
وطالبات الجامعة كليات نظرية وعملية من ذوي الاستخدام المرتقع للموبايل "مدمني الموبايل" لديهم مستوى منخفض الانتباه والذي يتمثل پِّ:(كثرة النسيان - تشتت الانتباه بسهولة بالمؤثرات

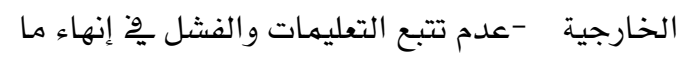


متابعة التعليمات التي تصدر عن الآخرين - لأمدات

يستجيبون بسرعة لمن ينادينهم وكأنهم أصماء -

يقومون بسلوكيات تعرض حياتهم إلي الخطر -

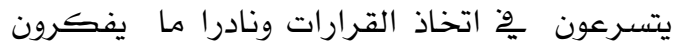
بالعواقب - يقل انتباههم بزيادة عدد المثيرات

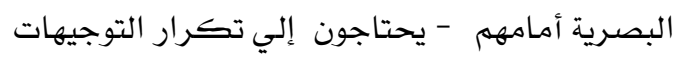
اللفظية اكتر من مرة - أعمالهم تخلو من النظام

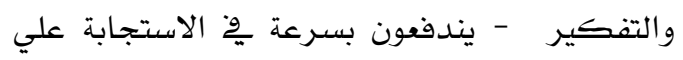
المواقف دون تفكير - يثورون ويغضبون لأتفه الأسباب) يؤدي وبلا شك إلى العديد من الحوادث بسبب استخدامهم للهاتف المحمول، كذلك كثرة ما تقوم السيارات بتتبيههم بحكم كونهم ساهيين

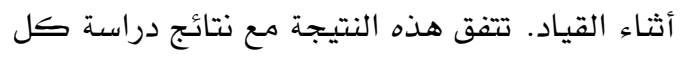
من:عبد العزيز (11 (Y)؛المصري (11) (1)؛ مغازي

\section{توصيات الدراسة}

1. الإعلاء من قيمة العهل الجهاعي وإثراء روح

المشاركة داخل الحياة الجامعية بهدف

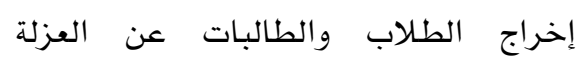

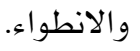

r. العهل على إصلاح أجهزة الإعلام للقيام بدورها التربوي والتوجيهي والإرشادي والنظر إلى عدم التوازن البرامجي بشيْ من

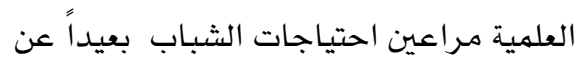
اللامبالاة والتقليد.

r. العمل على رفع الروح المعنوية لدى طلاب

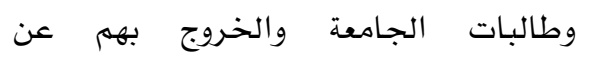
الاحباطات التي تلعب وسـائل الإعلام دوراً كبيراً

ع. وضع برامج علمية منظمة تستهدف أسس القيادة الأمثل للمركبات واحترام قواعد وقوانين حركة المرور والسير.
والحركة المرورية. ما توصلت إليه نتائج دراسـة الباحثة يتفق مع ما توصلت إليه نتائج دراسـة: عبد المرايد

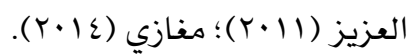

بالنسبة للتساؤل الرابع:هل توجد علاقة بين مكونات مقياسي الانتباه وقيادة المركبات والحركة المرورية لدي طلاب وطالبات الجامعة (مرتفعي استخدام الموبايل)؟ فقد أشارت النتائج إلى أن قيمة معامل الارتباط بين الانتباه والحركة المريايل المرورية لطلاب ولطالبات الجامعة (العينة ككل) -09.09 وهي ذات دلالة إحصائية عند مستوى1..•، بهعنى وجود علاقة ارتباطيه سالبة دالة إحصائيا عند مستوى دلالة (1 ..•) بين درجات الطلاب والطالبات مرتقعي استخدام الموبايل ودرجاتهم على مقياسي: الانتباه وقيادة المركبات والحركة المرورية.

ويمكن تفسير ذلك پِ ضوء أن مشكلات الانتباه"قصور الانتباه" يرتبط سالبا ودالا بالقدرة

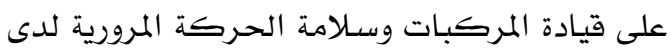

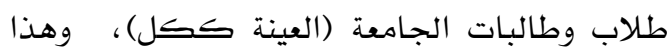
يشير إلى أن انخفاض مستوى الانتباه أي ارتفاع

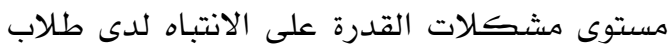
وطالبات الجامعة (العينة ككل)، يناظره انخفاض مِّ مستوى القدرة على القيادة السليمة للمركبات أي ارتفاع يِّ مستوى مشككلات الحركة المرورية. وترى الباحئة أن النتيجة تشير إلى وجود ارتباط سالب بين نقص الانتباه وكثرة حوادث الطرق والمخالفات بِّ قوانين المرور والسير أثناء قيادة المركبات لدي طلاب وطالبات الجامعة، وتعتبر نتيجة منطقيه هو حد ذاتها فنقص الانتباه لدي مدمني الموبايل من الطلاب والطالبات والتي تتمثل مظاهره وِّ علي سبيل المثال لا الحصر: (صعوبة

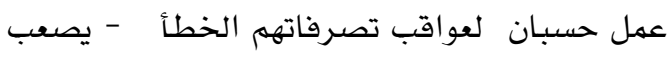

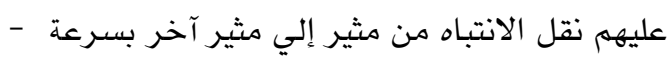
يصعب عليهم استهرار انتباههم علي المؤثرات البصرية لفترة طويلة - تشتت انتباههم السمعي بأقل عدد من المثيرات السهعية - يصعب عليهم 
النشاط المصورة "دراسات تطبيقية".القاهرة: دار

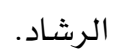

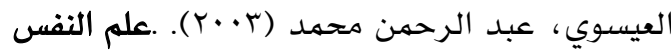

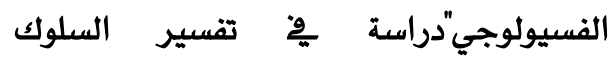

الإنساني". الإسكندرية : دار المعرفة الجامعية.

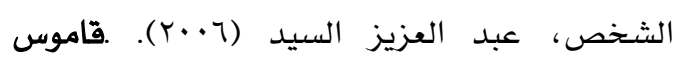

التربية الخاصة والتأهيل لذوى الاحتياجات

الخاصة. ط ؟.القاهرة:م كتبة الأنجلو المصرية.

الحربي، عبد الكريم عبد الله (عُ+r). الإنترنت

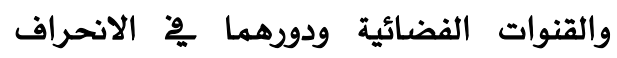

$$
\text { والجنوح، طب. الرياض. د.ن. }
$$

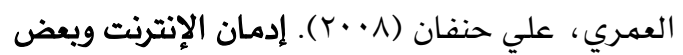
آثاره النفسية والاجتماعية لدى طلاب المرحلة الثانوية ِّْ محافظة محايل التعليمية. رسالة ماجستير. كلية التربية: جامعة الملك خالد.

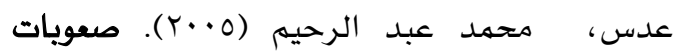
التعلم. عمان: دار الفكر للطباعة والنشر.

تش، مزري محمد (11 (r ). قصة فيس بوك ثورة

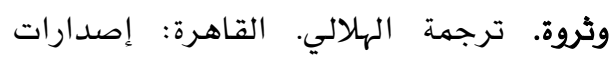

$$
\text { سطور الجديدة. }
$$

المصري، نعيم سعد (• (†). استخدامات الطلبة الجامعيين لمواقع التواصل الاجتماعي وأثره على وسائل الإعلام الأخرى: دراسة ميدانية على عينة من طلبة الكليات الفلسطينية. ورقة بحثية قدمت إلى مؤتمر كلية الإعلام بجامعة

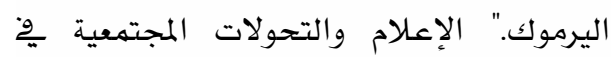

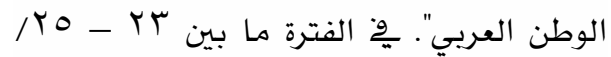

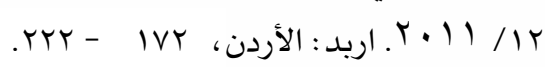

Friedman, J. \& kock, A. (1985). cognitive differences among three- year- old children with symptoms of hyperactivity. Inattention and aggression. Dissertation Abstracts international section $B$ : The sciences and Engineering.
المراجع

\section{References}

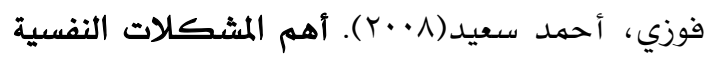

الناتجة عن إدمان المراهقين للإنترنت. .رسالة

ماجستير. معهد الدراسات العليا للطفولة: جامعة إلتان عين شهم.

فخري، أحمد محسن (1 •(Y). الإدمان على الإنترنت.

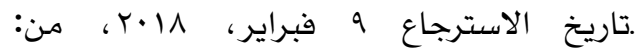
lkhttp://www.hayatnafs.com/mona3at _fi_alnafs/internet-addiction-notes.htm

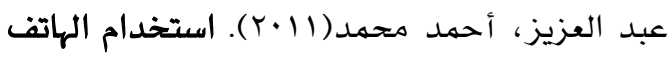

$$
\begin{aligned}
& \text { المتحرك أثناء القيادة الطريق الأقصر نحو }
\end{aligned}
$$

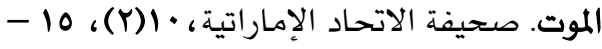

$$
\begin{aligned}
& .1 \mathrm{~V}
\end{aligned}
$$

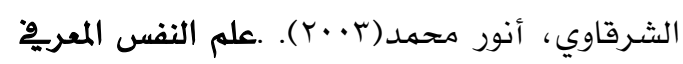

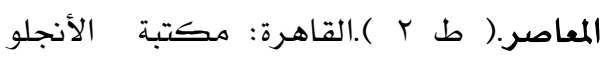

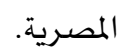

عزب، حسام الدين محمود (1 - + ). إدمان الإنترنت وعلاقته ببعض أبعاد الصحة النفسية لدى الدى الدمان الانترني طلاب المرحلة الثانوية - الوجه الآخر

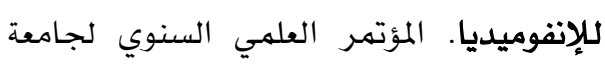
عين شهس- الطفل والبيئة. معهد الدراسات

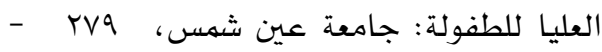
RT

عساف، دينا محمد (Y). (†). استخدامات المراهقين

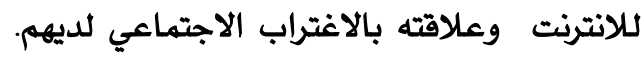

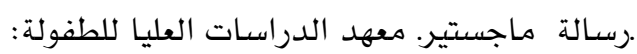
جامعة عين شهس. مغازي، سليمان عبد ربه (ع|·r). الهاتف الجوال

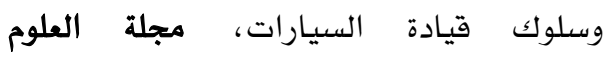

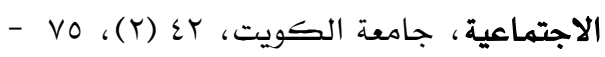
$.11 \%$ محمد ، عادل عبد الله (ب...\%). تعديل السلوك للأطفال المتخلفين عقليا باستخدام جداول 